\title{
Enantioselective Pd-Catalyzed Trimethylenemethane Cycloadditions of All-Carbon 1,4-Dipoles
}

\section{Category}

Metals in Synthesis

\section{Key words}

palladium catalysis

enantioselectivity

cycloaddition

Synta

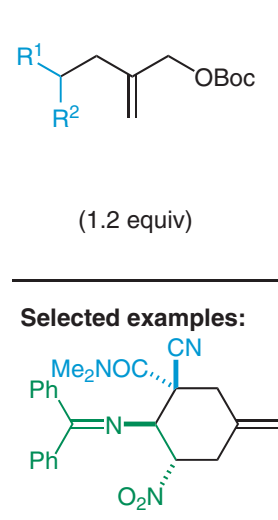

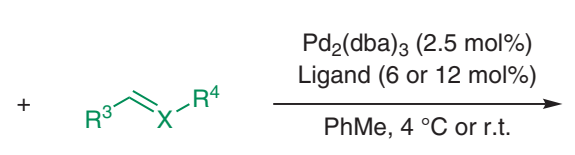

$(0.1 \mathrm{mmol})$

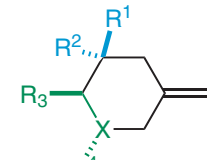

$\mathrm{R}^{4}$

32 examples

up to $94 \%$ yield up to $98 \%$ ee, $d r>15: 1$

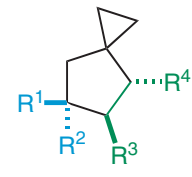

4 examples up to $80 \%$ yield up to $91 \%$ ee, $d r>15: 1$
$94 \%$ yield $87 \%$ ee, dr $>15: 1$

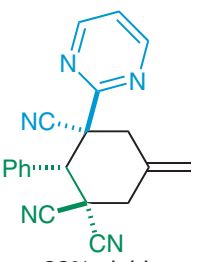

$83 \%$ yield $85 \%$ ee, $d r=6.2: 1$

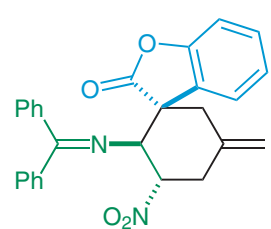

$64 \%$ yield $64 \%$ yield
eee $, \mathrm{dr}=5.3: 1$

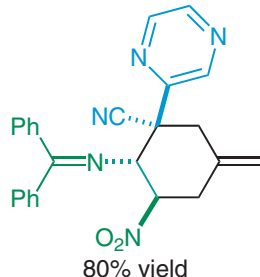

$91 \%$ ee, $\mathrm{dr}=7.1: 1$

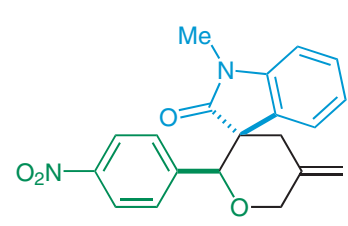

$91 \%$ yield $43 \%$ ee, $\mathrm{dr}=14: 1$

\section{Synthetic application:}

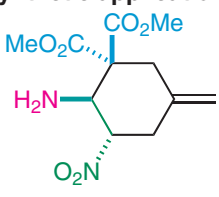

$92 \%$ yield

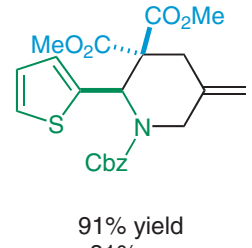

$81 \%$ ee

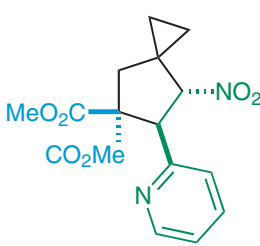

$63 \%$ yield $82 \%$ ee, dr $>15: 1$
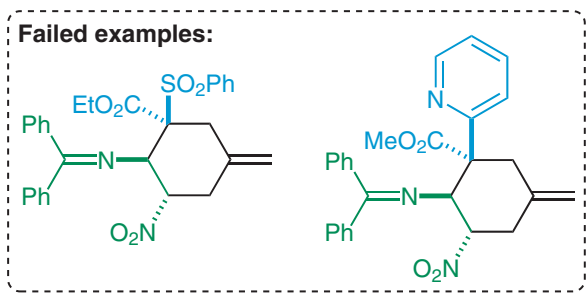

Significance: Trost and co-workers report the asymmetric syntheses of all-carbon chiral cyclohexanes and spiro[2.4]heptanes using palladium-catalyzed cycloadditions of aliphatic 1,4-dipoles. Using various phosphoramidite and diamidophosphite ligands, several biologically relevant scaffolds were generated in good regio-, diastereo- and enantioselectivity. The synthetic utility was demonstrated through gram-scale syntheses of each scaffold, and derivatizations included the ozonolysis and hydrolysis reactions shown.
Comment: Upon scale up, the palladium and ligand loading could be decreased to 2 and $4 \mathrm{~mol} \%$, respectively, and the cyclohexane products were formed with higher regioselectivity than the spirocycles. Interestingly, a resonance effect between the pyridine nitrogen and palladium cation center was found to be necessary for the examples with heterocyclic arenes as the second electron-withdrawing group. 